\title{
Reação de genótipos de batata ao nematoide-das-galhas Meloidogyne spp. em campos naturalmente infestados
}

\author{
J.B. Pinheiro ${ }^{1}$, G.O. da Silva ${ }^{2 *}$, D. Biscaia ${ }^{3}$, A.G. Macêdo ${ }^{4}$, C.F.Ragassi ${ }^{1}$, D.C. Santiago ${ }^{5}$
}

Recebido: 19/02/2018

Aceito: 06/04/2018

Acessíveis on-line: Junho 2018

\begin{abstract}
Resumo
O objetivo deste trabalho foi verificar a reação de genótipos de batata aos nematoide-das-galhas Meloidogyne spp. Foram realizados dois experimentos em campo, o primeiro com 12 clones e uma cultivar de batata, em um campo naturalmente infestado com Meloidogyne incognita raça 1; no segundo, foram utilizados 12 clones e duas cultivares de batata, em um campo infestado com Meloidogyne javanica. Os experimentos foram conduzidos em delineamento de blocos ao acaso com quatro e seis repetições, respectivamente. Aos 111 dias após os plantios foi realizada coleta do solo, a colheita das plantas, e as avaliações para população final de nematoides no solo, número total de juvenis extraídos da superfície externa dos tubérculos (casca dos tubérculos), cálculo do Fator de Reprodução (FR), massa de tubérculos, número de tubérculos por planta e massa média de tubérculos. Os dados foram submetidos à análise de variância e agrupamento de médias dos tratamentos por Scott-Knott. Foi verificada predominância de variação de ordem ambiental em relação à genética para os caracteres que medem a resistência às espécies de nematoides, e menor precisão experimental para caracteres de rendimento no primeiro experimento e maiores para o segundo. No primeiro experimento, os clones F161-0207, F131-26-08 e F76-01-07 foram classificados como resistentes. Os clones F102-22-07, F131-06-08, F156-19-06, F161-02-07, F183-08-01, F50-01-08 e F76-01-07 apresentaram FR maior que a unidade, mas foram incluídos no mesmo grupo dos clones F161-02-07, F131-2608 e F76-01-07 na análise de agrupamento de médias. Os clones F22-01-08, F102-22-07, F13106-08, F131-26-08, F161-02-07, F183-01-08 e F97-07-08 apresentaram os melhores resultados para caracteres relacionados ao rendimento de tubérculos. No segundo experimento, todos os clones e cultivares foram considerados suscetíveis, com aumento nas populações do nematoide, e muito embora não foi possível diferenciar os genótipos avaliados quanto ao FR, houve grande variação na resposta dos genótipos. Os clones C2519-1206, F102-22-07, F37-01-08, F208-0106, F31-05-08 e F32-02-06 apresentaram os melhores resultados para caracteres relacionados ao rendimento de tubérculos.
\end{abstract}

Palavras chave adicionais: Solanum tuberosum L., Meloidogyne incognita raça 1, Meloidogyne javanica, fator de reprodução, resistência.

\footnotetext{
* Autor para correspondência. Correspondência eletrônica: giovani.olegario@embrapa.br

${ }^{1}$ Pesquisador da Embrapa, Brasília, Distrito Federal, Brasil.

${ }^{2}$ Pesquisador da Embrapa, Canoinhas, Santa Catarina, Brasil.

${ }^{3}$ Analista da Embrapa, Brasília, Distrito Federal, Brasil.

${ }^{4}$ Professora da Universidade de Brasília, Brasília, Distrito Federal, Brasil.

${ }^{5}$ Professora da Universidade Estadual de Londrina, Londrina, Paraná, Brasil.
} 


\section{Reaction of potato genotypes to the root-knot nematode Meloidogyne spp. in naturally infested fields}

\section{Summary}

The research studied potato genotypes for the reaction to Meloidogyne spp. Two experiments were carried out in the field, the first with 12 potato clones and one cultivar in a field naturally infested with Meloidogyne incognita race 1 and the second with 12 clones and two potato cultivars in a field infested with Meloidogyne javanica. Randomized complete block was the experimental design with 4 and 6 replications, respectively. At 111 days after planting, soil was collected, plants were harvested and evaluations were carried out for estimating final population of nematodes in the soil, total number of juveniles extracted from external tuber surface (tuber skin), Reproduction Factor (RF), tuber mass, number of tubers per plant and tuber average mass. Data were submitted to analysis of variance and grouping of means by Scott-Knott. It was verified a predominance of variation of environmental order in relation to the genetics for the characters that measure the resistance to the species of nematodes, and lower experimental precision for yield characters in the first experiment and greater for the second one. For the first experiment, clones F161-02-07, F131-26-08 and F76-01-07 were classified as resistant. Clones F102-22-07, F131-06-08, F156-19-06, F161-02-07, F183-08-01, F50-01-08 and F76-01-07 showed RF higher than 1. Nevertheless, they were included in the same group as F161-02-07, F131-26-08 and F76-01-07 by the grouping analysis. Clones F2201-08, F102-22-07, F131-06-08, F131-26-08, F161-02-07, F183-01-08 and F97-07-08 presented the best results for traits related to tuber yield. In the second experiment, all clones and all cultivars were susceptible, with an increase in nematode populations, and although it was not possible to differentiate the genotypes evaluated for RF, there was a great variation in the response of the genotypes. Clones C2519-1206, F102-22-07, F37-01-08, F208-01-06, F3105-08 and F32-02-06 presented the best results for traits related to tuber yield.

Addicional key words: Solanum tuberosum L., Meloidogyne incognita race 1, Meloidogyne javanica, reproduction factor, resistance.

\section{Introdução}

Mais de 140 espécies de fitonematoides, distribuídas em 45 gêneros, têm sido encontradas associadas aos cultivos de batata em todo o mundo (Prasad 1993), cujas perdas médias anuais causadas por nematoides são estimadas em $12 \%$ da produção, podendo comprometer até $100 \%$ (Pinheiro e Lopes 2011). O gênero Meloidogyne, que compreende os nematoides formadores de galhas, está associado a uma enorme gama de hospedeiros, sendo responsáveis por danos econômicos em diversas culturas em todo mundo (Freitas et al. 2001). No Brasil, devido à extensão dos danos causados a diversas culturas e a sua ampla distribuição, Meloidogyne incognita (Kofoid \& White) Chitwood e $M$. javanica (Treub) Chitwood são consideradas as de maior importância. $\mathrm{Na}$ cultura da batata
(Solanum tuberosum L.) estas espécies, também, se destacam pela maior ocorrência em regiões produtoras no país, grande potencial de dano (Charchar e Moita 2001, Pinheiro e Lopes 2011) e devido à sua capacidade reprodutiva em genótipos suscetíveis (Vovlas et al. 2005).

Entre as espécies de Meloidogyne relacionadas à cultura no Brasil, registra-se maior ocorrência de $M$. incognita (Kofoid e White) Chitwood, M. javanica (Treub) Chitwood, $M$. arenaria (Neal) Chitwood e M. hapla Chitwood. As três primeiras são mais adaptadas a climas com grande variação de temperatura $\left(18^{\circ} \mathrm{C}-32^{\circ} \mathrm{C}\right)$ e a última, a climas mais amenos a frio, sendo que as duas primeiras espécies apresentam maior distribuição em regiões produtoras de batata no país (Charchar 2001, Pinheiro e Lopes 2011). 
Os danos causados pelo nematoide-dasgalhas não estão associados somente à redução no peso nos tubérculos, mas às alterações físico-químicas em resposta à infecção, com interferência direta na qualidade comercial dos tubérculos (Silva e Santos 2007). Este patógeno, ao penetrar no sistema radicular da planta, pode induzir à formação de galhas nas raízes, afetar negativamente o desenvolvimento da planta em função da menor absorção de água e nutrientes e, ainda, causar galhas nos tubérculos, depreciando-os comercialmente (Lima-Medina et al. 2014).

Entre os métodos de controle mais difundidos para os fitonematoides estão a utilização de produtos químicos, a rotação de culturas, a utilização de plantas antagonistas, o alqueive e o emprego da resistência genética (Almeida et al. 2012). E, a associação de mais de uma medida de controle na maioria das vezes é a melhor opção (Pinheiro et al. 2013). O uso de cultivares de batata resistentes a Meloidogyne spp. é uma das alternativas mais desejáveis, por apresentar custo mais baixo além de maior eficácia. A resistência genética, além de ser uma ferramenta importante para o manejo das culturas, é também vantajosa para reduzir a multiplicação de nematoides, colaborando também para a safra seguinte (Starr e Roberts 2004). Porém, no Brasil, são escassos os materiais disponíveis no mercado, assim como as informações sobre a resistência de muitos dos genótipos aos nematoides-das-galhas (Lima-Medina et al. 2014).

Assim, o objetivo deste trabalho foi verificar a reação de genótipos de batata em áreas de campo naturalmente infestadas por Meloidogyne incognita e M. javanica.

\section{Material e Métodos}

Dois experimentos foram realizados em campo experimental da Embrapa
Hortaliças localizado na Cidade do Gama, Distrito Federal. Em cada experimento foi avaliada a reação de um conjunto de clones e cultivares de batata ao parasitismo do nematoide-das-galhas.

No primeiro experimento, foram avaliados os clones F102-22-07, F110-01-07, F13106-08, F131-26-08, F156-19-06, F161-0207, F183-01-08, F21-09-07, F22-01-08, F50-01-08, F76-01-07, F97-07-08 e a cultivar Catucha. Tubérculos-semente do tipo II (41 $\mathrm{mm}$ a $50 \mathrm{~mm}$ de diâmetro) foram plantados no dia 10 de junho de 2014 em delineamento experimental de blocos ao acaso com quatro repetições e parcelas compostas por uma linha com cinco plantas. $\mathrm{O}$ espaçamento foi de 0,30 $\mathrm{m}$ entre plantas e $0,80 \mathrm{~m}$ entre linhas. $\mathrm{O}$ campo, previamente cultivado com mandioquinha-salsa (Arracacia xanthorrhiza), estava infestado por $M$. incognita raça 1 com média de aproximadamente 192,32 juvenis de $2^{\circ}$ estádio (J2) por $150 \mathrm{~cm}^{3}$ de solo.

No segundo experimento, foram avaliados os clones C2519-1206, F102-22-07, F18909-06, F208-01-06, F22-01-08, F23-11-06, F23-24-06, F31-05-08, F32-02-06, F32-1106, F37-01-08, F38-03-07 e as cultivares Agata e Asterix. Tubérculos-sementes do tipo II (41 $\mathrm{mm}$ a $50 \mathrm{~mm}$ de diâmetro) de cada genótipo foram plantados no dia 18 de junho de 2015 no delineamento experimental blocos ao acaso com seis repetições e parcelas compostas por uma linha com cinco plantas. O espaçamento foi de $0,30 \mathrm{~m}$ entre plantas e $0,80 \mathrm{~m}$ entre linhas. O campo, previamente cultivado com Sorghum halepense e cultivado anteriormente com tomate, estava infestado por $M$. javanica, com média em torno de $36 \mathrm{~J} 2$ por $150 \mathrm{~cm}^{3}$ de solo.

A identificação das espécies de Meloidogyne presentes foi realizada previamente nas duas áreas onde os experimentos foram instalados $\mathrm{e}$ 
conduzidos. Para isso, fêmeas de Meloidogyne foram extraídas de mandioquinha-salsa e de Sorghum halepense para identificação no Laboratório de Nematologia da Embrapa Hortaliças. A caracterização isoenzimática foi realizada conforme metodologia adaptada de Carneiro e Almeida (2001). A raça de $M$. incognita foi identificada, no primeiro experimento, por meio do teste de hospedeiros diferenciadores (Taylor e Sasser 1978).

Em ambos os experimentos, o solo foi convencionalmente preparado com aração e gradagem. Em seguida, foram aplicados $200 \mathrm{~g}$ do formulado comercial NPK 00-2020 por metro linear de sulco $(2500 \mathrm{~kg} / \mathrm{ha})$ como adubação de plantio. Na amontoa, 30 dias após o plantio, foram aplicadas $24 \mathrm{~g}$ de ureia por metro linear $(300 \mathrm{~kg} / \mathrm{ha})$, como adubação de cobertura. Uma fileira contínua de batata foi plantada ao redor dos experimentos para servir de bordadura. A irrigação foi realizada por aspersão conforme a necessidade da cultura durante toda a condução dos experimentos. No momento dos plantios, cinco subamostras de solo foram coletadas em pontos equidistantes de cada parcela, para quantificação da população inicial do nematoide. Após a coleta, estas amostras foram homogeneizadas e a quantia de $1 \mathrm{~kg}$ foi retirada para constituir a amostra composta. As amostras foram processadas em laboratório de acordo com Jenkins (1964). Após a extração dos nematoides, a população inicial de $\mathrm{J} 2$ de Meloidogyne por $150 \mathrm{~cm}^{3}$ de solo foi quantificada de cada parcela no plantio. Nas colheitas, 111 dias após os plantios, foram avaliadas a população final de $\mathrm{J} 2$ de Meloidogyne spp. por $150 \mathrm{~cm}^{3}$ de solo referente a cada parcela, número total de juvenis extraídos da superfície externa de 10 tubérculos $( \pm 3$ $\mathrm{mm}$ de espessura) de acordo com Hussey e Barker (1973), massa de tubérculos $\left(\mathrm{t} \mathrm{ha}^{-1}\right)$, número de tubérculos/planta e fator de reprodução (FR) estimado com base em Oostenbrink (1966): (população final na colheita + número total de juvenis extraídos da superfície externa dos tubérculos)/população inicial no plantio). Plantas com FR $<1,00$ foram consideradas resistentes, enquanto as com $\mathrm{FR} \geq 1,00$ foram consideradas suscetíveis.

Devido à heterogeneidade de variâncias, os dados, com exceção daqueles que mediam o rendimento de tubérculos, foram transformados em $\log _{10}(\mathrm{x}+1)$. Posteriormente, todos os dados foram submetidos à análise de variância e agrupamento de médias de tratamentos por Scott-Knott (1974), utilizando-se o programa Genes (Cruz 2013).

\section{Resultados e Discussão}

Para o conjunto de genótipos avaliados no primeiro experimento (2014) (Tabelas $1 \mathrm{e}$ 2 ), houve diferenças significativas para quase todos os caracteres, exceto para a população inicial de nematoides no solo. Os coeficientes de variação indicam maior precisão experimental para os caracteres população inicial $(11,21 \%)$ e final $(19,22 \%)$ de nematoides no solo, e menor para os demais caracteres, com variação de 35,44 a $53,00 \%$. 
Tabela 1. População inicial e final de juvenis de segundo estádio, número de juvenis na casca dos tubérculos e fator de reprodução de Meloidogyne incognita raça 1 em campo naturalmente infestado, cultivado com treze genótipos de batata.

\begin{tabular}{|c|c|c|c|c|}
\hline \multirow{2}{*}{ Clones } & ${ }^{1} \mathbf{P i} /$ & ${ }^{2} \mathbf{P f}$ & \multirow{2}{*}{${ }^{3}$ NTJSET } & \multirow{2}{*}{${ }^{4} \mathbf{F R}$} \\
\hline & \multicolumn{2}{|c|}{$150 \mathrm{~cm}^{3}$ de solo } & & \\
\hline F102-22-07 & $187,50 \mathrm{a}^{5}$ & $362,50 \mathrm{~b}$ & $3,58 \mathrm{~b}$ & $1,95 \mathrm{~b}$ \\
\hline F110-01-07 & $200,00 \mathrm{a}$ & $918,75 \mathrm{a}$ & $27,45 \mathrm{a}$ & $4.71 \mathrm{a}$ \\
\hline F131-06-08 & $250,00 \mathrm{a}$ & $562,50 \mathrm{~b}$ & 33,49 a & $2,38 \mathrm{~b}$ \\
\hline F131-26-08 & $250,00 \mathrm{a}$ & $187,50 \mathrm{~b}$ & $52,67 \mathrm{a}$ & $0,96 \mathrm{~b}$ \\
\hline F156-19-06 & $150,00 \mathrm{a}$ & $331,25 \mathrm{~b}$ & $20,07 \mathrm{a}$ & $2,34 \mathrm{~b}$ \\
\hline F161-02-07 & $200,00 \mathrm{a}$ & $81,25 \mathrm{~b}$ & $3,14 \mathrm{~b}$ & $0,42 \mathrm{~b}$ \\
\hline F183-01-08 & $225,00 \mathrm{a}$ & $593,75 \mathrm{~b}$ & $24,73 \mathrm{a}$ & $2,75 \mathrm{~b}$ \\
\hline F21-09-07 & $187,50 \mathrm{a}$ & $1631,25 \mathrm{a}$ & $16,25 \mathrm{a}$ & $8,79 \mathrm{a}$ \\
\hline F22-01-08 & $200,00 \mathrm{a}$ & $1737,50 \mathrm{a}$ & $43,22 \mathrm{a}$ & $8,90 \mathrm{a}$ \\
\hline F50-01-08 & $175,00 \mathrm{a}$ & $231,25 \mathrm{~b}$ & 29,66 a & $1,49 \mathrm{~b}$ \\
\hline F76-01-07 & $200,00 \mathrm{a}$ & $162,50 \mathrm{~b}$ & $34,89 \mathrm{a}$ & $0,99 \mathrm{~b}$ \\
\hline F97-07-08 & $200,00 \mathrm{a}$ & $1718,75 \mathrm{a}$ & $66,27 \mathrm{a}$ & $8,92 \mathrm{a}$ \\
\hline Catucha & 75,19 a & $935,94 \mathrm{a}$ & $20,18 \mathrm{a}$ & $12,72 \mathrm{a}$ \\
\hline Média geral & 192,32 & 727,28 & 28,89 & 4,41 \\
\hline $\mathrm{CV} \%{ }^{6}$ & 11,21 & 19,22 & 47,01 & 53,00 \\
\hline $\mathrm{CVg} / \mathrm{CV}^{7}$ & - & 0,76 & 0,57 & 0,74 \\
\hline
\end{tabular}

${ }^{1}$ População inicial de juvenis de $2^{\circ}$ estádio (J2) por $150 \mathrm{~cm}^{3}$ de solo; ${ }^{2}$ População final de $\mathrm{J} 2$ por $150 \mathrm{~cm}^{3}$ de solo; ${ }^{3}$ Número total de juvenis extraídos da superfície externa dos tubérculos $( \pm 3 \mathrm{~mm}$ de espessura) de acordo com Hussey \& Barker (1973); ${ }^{4}$ Fator de reprodução com base em Oostenbrink (1966) (população final na colheita + NTJSET)/população inicial no plantio). Plantas com FR $<1,00=$ resistentes. FR $\geq 1,00=$ suscetíveis. ${ }^{5}$ Valores na mesma coluna seguidos da mesma letra não diferem entre si pelo teste Scott-Knott $(\mathrm{P}<0,05) .{ }^{6}$ Coeficiente de variação em percentagem. ${ }^{7} \mathrm{CVg} / \mathrm{CV}$ : relação entre coeficiente de variação genotípico e fenotípico.

Tabela 2. Agrupamento de médias entre clones de batata para caracteres de rendimento de tubérculos em campo infestado com Meloidogyne incognita raça 1.

\begin{tabular}{lccc}
\hline Clones & ${ }^{1}$ MT & ${ }^{2}$ MMT & ${ }^{3} \mathbf{N T}$ \\
\hline F102-22-07 & $7,94 \mathrm{~b}^{4}$ & $62,38 \mathrm{a}$ & $2,65 \mathrm{c}$ \\
F110-01-07 & $27,81 \mathrm{~b}$ & $55,39 \mathrm{~b}$ & $11,95 \mathrm{~b}$ \\
F131-06-08 & $16,02 \mathrm{~b}$ & $77,92 \mathrm{a}$ & $5,55 \mathrm{c}$ \\
F131-26-08 & $11,69 \mathrm{~b}$ & $63,07 \mathrm{a}$ & $3,65 \mathrm{c}$ \\
F156-19-06 & $6,31 \mathrm{~b}$ & $32,24 \mathrm{~b}$ & $4,75 \mathrm{c}$ \\
F161-02-07 & $16,25 \mathrm{~b}$ & $85,55 \mathrm{a}$ & $5,40 \mathrm{c}$ \\
F183-01-08 & $13,35 \mathrm{~b}$ & $90,42 \mathrm{a}$ & $3,90 \mathrm{c}$ \\
F21-09-07 & $11,90 \mathrm{~b}$ & $35,19 \mathrm{~b}$ & $8,20 \mathrm{~b}$ \\
F22-01-08 & $48,00 \mathrm{a}$ & $57,67 \mathrm{~b}$ & $20,40 \mathrm{a}$ \\
F50-01-08 & $13,15 \mathrm{~b}$ & $44,52 \mathrm{~b}$ & $8,05 \mathrm{~b}$ \\
F76-01-07 & $13,73 \mathrm{~b}$ & $31,31 \mathrm{~b}$ & $9,80 \mathrm{~b}$ \\
F97-07-08 & $17,71 \mathrm{~b}$ & $78,89 \mathrm{a}$ & $5,95 \mathrm{c}$ \\
Catucha & $21,66 \mathrm{~b}$ & $46,13 \mathrm{~b}$ & $10,43 \mathrm{~b}$ \\
\hline Média geral & 17,34 & 58,51 & 7,74 \\
CV\% & 53,01 & 35,74 & 52,91 \\
CVg/CV & 1,06 & 0,83 & 1,04 \\
\hline
\end{tabular}

${ }^{1}$ MTT: massa total de tubérculos em $\mathrm{t} \mathrm{ha}{ }^{-1} ;{ }^{2}$ MMT: massa média de tubérculos em $\mathrm{g}$ tubérculo ${ }^{-1} ;{ }^{3} \mathrm{NT}$ : número de tubérculos por planta, ${ }^{4}$ Valores na mesma coluna seguidos da mesma letra não diferem entre si pelo teste Scott-Knott $(\mathrm{P}<0,05) ;{ }^{5} \mathrm{CV}$ : coeficiente de variação em percentagem, ${ }^{6} \mathrm{CVg} / \mathrm{CV}$ : relação entre coeficiente de variação genotípico e fenotípico. 
A relação entre os coeficientes de variação genotípico e fenotípico indicam se a situação é favorável à seleção. Quando superior à unidade, indica a predominância da variação genética em comparação com a ambiental (Cruz et al. 2012). No presente estudo, esta relação foi maior para os caracteres de rendimento de tubérculos (peso total em toneladas por ha ${ }^{-1}$ e número de tubérculos por planta, Tabela 2) e menor para as demais variáveis relacionadas diretamente aos nematoides, principalmente, o número de juvenis extraídos na superfície dos tubérculos $(0,57)$.

Quanto aos caracteres de rendimento, como massa e número de tubérculos, estes são caracteres quantitativos e, portanto, sofrem maior influência ambiental do que os caracteres qualitativos. Era esperado, dessa forma, maior coeficiente de variação ambiental para os caracteres quantitativos (Silva et al. 2006). Com relação ao FR e ao número de juvenis na superfície externa dos tubérculos, valores de coeficiente de variação em torno de $50 \%$ estão próximos aos verificados na literatura, para experimentos de campo com batata (Charchar e Moita 2001; Pinheiro et al. 2013).
Para o conjunto de genótipos avaliados no segundo experimento (2015) (Tabelas 3 e 4), não houve diferenças significativas para os caracteres que quantificam a população e a reprodução dos nematoides. Já, para os caracteres que medem o rendimento de tubérculos, diferenças significativas foram observadas. A precisão experimental também foi maior para os caracteres de rendimento, variando de 21,45 a 28,76\%. Já, para os demais caracteres que medem a quantificação e reprodução dos nematoides, foi menor, entre 36,80 a $71,13 \%$. A relação entre os coeficientes de variação genotípico e fenotípico indica que uma maior proporção da variação de ordem genética foi obtida para os caracteres de rendimento, e que a maior parte da variação para os caracteres que medem a quantidade e a multiplicação dos nematoides, captada pelos quadrados médios da análise de variância, são devido às causas ambientais. Isso significa que as condições ambientais e experimentais não foram favoráveis para a determinação do nível de resistência dos genótipos aos nematoides no caso do segundo experimento (M. javanica), provavelmente devido à natureza destes caracteres, pois a campo os nematoides não são distribuídos uniformemente. 
Tabela 3. População inicial e final de juvenis de segundo estádio, número de juvenis na casca dos tubérculos e fator de reprodução de Meloidogyne javanica em campo naturalmente infestado cultivado com quatorze genótipos de batata.

\begin{tabular}{|c|c|c|c|c|}
\hline \multirow[b]{2}{*}{ Clones } & ${ }^{1} \mathbf{P i}$ & ${ }^{2} \mathbf{P f}$ & \multirow{2}{*}{${ }^{3}$ NTJSET } & \multirow{2}{*}{${ }^{4} \mathbf{F R}$} \\
\hline & \multicolumn{2}{|c|}{$150 \mathrm{~cm}^{3}$ de solo } & & \\
\hline Agata & $96,17 a^{5}$ & $163,33 \mathrm{a}$ & $43,33 \mathrm{a}$ & $2,15 \mathrm{a}$ \\
\hline Asterix & $33,83 \mathrm{a}$ & $73,33 \mathrm{a}$ & $102,39 \mathrm{a}$ & $5,19 \mathrm{a}$ \\
\hline C2519-1206 & $5,00 \mathrm{a}$ & $10,00 \mathrm{a}$ & $82,47 \mathrm{a}$ & $18,49 \mathrm{a}$ \\
\hline F102-22-07 & $25,67 \mathrm{a}$ & $123,33 \mathrm{a}$ & $171,39 \mathrm{a}$ & $7,02 \mathrm{a}$ \\
\hline F189-09-06 & $9,17 \mathrm{a}$ & $13,33 \mathrm{a}$ & $64,87 \mathrm{a}$ & $8,53 \mathrm{a}$ \\
\hline F208-01-06 & $59,00 \mathrm{a}$ & $166,67 \mathrm{a}$ & $160,95 \mathrm{a}$ & $5,55 \mathrm{a}$ \\
\hline F22-01-08 & $25,50 \mathrm{a}$ & $103,33 \mathrm{a}$ & $17,11 \mathrm{a}$ & $4,72 \mathrm{a}$ \\
\hline F23-11-06 & $46,17 \mathrm{a}$ & $323,33 \mathrm{a}$ & $82,09 \mathrm{a}$ & $8,78 \mathrm{a}$ \\
\hline F23-24-06 & $9,17 \mathrm{a}$ & $186,67 \mathrm{a}$ & $35,33 \mathrm{a}$ & $24,22 \mathrm{a}$ \\
\hline F31-05-08 & $25,33 \mathrm{a}$ & $113,33 \mathrm{a}$ & $28,28 \mathrm{a}$ & $5,59 \mathrm{a}$ \\
\hline F32-02-06 & $5,00 \mathrm{a}$ & $330,00 \mathrm{a}$ & $42,22 \mathrm{a}$ & $74,44 \mathrm{a}$ \\
\hline F32-11-06 & $96,17 \mathrm{a}$ & $260,00 \mathrm{a}$ & $68,12 \mathrm{a}$ & $3,41 \mathrm{a}$ \\
\hline F37-01-08 & $25,50 \mathrm{a}$ & $83,33 \mathrm{a}$ & $31,32 \mathrm{a}$ & $4,50 \mathrm{a}$ \\
\hline F38-03-07 & $41,83 \mathrm{a}$ & $346,67 \mathrm{a}$ & $92,59 \mathrm{a}$ & $10,50 \mathrm{a}$ \\
\hline Média geral & 35,96 & 164,05 & 73,07 & 13,08 \\
\hline $\mathrm{CV} \%^{6}$ & 71,13 & 36,80 & 68,65 & 70,38 \\
\hline $\mathrm{CVg} / \mathrm{CV}^{7}$ & - & 0,28 & 0,00 & 0,06 \\
\hline
\end{tabular}

${ }^{1}$ População inicial de juvenis de $2^{\circ}$ estádio (J2) por $150 \mathrm{~cm}^{3}$ de solo; ${ }^{2}$ População final de $\mathrm{J} 2$ por $150 \mathrm{~cm}^{3}$ de solo; ${ }^{3}$ Número total de juvenis extraídos da superfície externa dos tubérculos $( \pm 3 \mathrm{~mm}$ de espessura) de acordo com Hussey \& Barker (1973); ${ }^{4}$ Fator de reprodução com base em Oostenbrink (1966) (população final na colheita + NTJSET)/população inicial no plantio). Plantas com FR $<1,00=$ resistentes. FR $\geq 1,00=$ suscetíveis. ${ }^{5}$ Valores na mesma coluna seguidos da mesma letra não diferem entre si pelo teste Scott-Knott $(\mathrm{P}<0,05) .{ }^{6}$ Coeficiente de variação em percentagem. ${ }^{7} \mathrm{CVg} / \mathrm{CV}$ : relação entre coeficiente de variação genotípico e fenotípico.

Tabela 4. Agrupamento de médias entre clones de batata para caracteres de rendimento de tubérculos de batata em campo infestado com Meloidogyne javanica.

\begin{tabular}{lccc}
\hline Clones & ${ }^{1} \mathbf{M T T}$ & ${ }^{2} \mathbf{M M T}$ & ${ }^{3} \mathbf{N T}$ \\
\hline Agata & $32,00 \mathrm{~b}^{4}$ & $100,11 \mathrm{c}$ & $7,77 \mathrm{~b}$ \\
Asterix & $41,72 \mathrm{a}$ & $125,92 \mathrm{~b}$ & $8,17 \mathrm{~b}$ \\
C2519-1206 & $21,25 \mathrm{~b}$ & $171,39 \mathrm{a}$ & $3,37 \mathrm{c}$ \\
F102-22-07 & $25,79 \mathrm{~b}$ & $182,95 \mathrm{a}$ & $3,57 \mathrm{c}$ \\
F189-09-06 & $33,46 \mathrm{~b}$ & $109,27 \mathrm{c}$ & $7,47 \mathrm{~b}$ \\
F208-01-06 & $40,13 \mathrm{a}$ & $131,67 \mathrm{~b}$ & $7,57 \mathrm{~b}$ \\
F22-01-08 & $39,03 \mathrm{a}$ & $105,35 \mathrm{c}$ & $9,97 \mathrm{a}$ \\
F23-11-06 & $40,22 \mathrm{a}$ & $110,39 \mathrm{c}$ & $9,23 \mathrm{~b}$ \\
F23-24-06 & $47,99 \mathrm{a}$ & $94,73 \mathrm{c}$ & $12,63 \mathrm{a}$ \\
F31-05-08 & $47,32 \mathrm{a}$ & $122,88 \mathrm{~b}$ & $9,50 \mathrm{~b}$ \\
F32-02-06 & $40,56 \mathrm{a}$ & $122,46 \mathrm{~b}$ & $8,57 \mathrm{~b}$ \\
F32-11-06 & $40,78 \mathrm{a}$ & $100,10 \mathrm{c}$ & $10,03 \mathrm{a}$ \\
F37-01-08 & $29,28 \mathrm{~b}$ & $148,99 \mathrm{a}$ & $4,83 \mathrm{c}$ \\
F38-03-07 & $37,43 \mathrm{a}$ & $80,16 \mathrm{c}$ & $11,17 \mathrm{a}$ \\
\hline Média geral & 36,93 & 121,88 & 8,13 \\
CV\% & 5 & 21,45 & 28,76 \\
CVg/CV & 21,66 & 1,04 & 1,08 \\
\hline
\end{tabular}

${ }^{1}$ MTT: massa total de tubérculos em $\mathrm{t} \mathrm{ha}^{-1} ;{ }^{2} \mathrm{MMT}$ : massa média de tubérculos em $\mathrm{g}$ tubérculo ${ }^{-1} ;{ }^{3} \mathrm{NT}$ : número de tubérculos por planta; ${ }^{4}$ Valores na mesma coluna seguidos da mesma letra não diferem entre si pelo teste ScottKnott $(\mathrm{P}<0,05) ;{ }^{5} \mathrm{CV}$ : coeficiente de variação em percentagem; ${ }^{6} \mathrm{CVg} / \mathrm{CV}$ : relação entre o coeficiente de variação genotípico e fenotípico. 
As populações iniciais e finais no solo foram maiores para o primeiro experimento $(M$. incognita raça 1$)$, mas a taxa de multiplicação foi menor (3,78 vezes) (Tabela 1). Já, no segundo experimento, as populações iniciais e finais de $M$. javanica foram menores, entretanto a taxa de multiplicação foi maior (4,56 vezes) e o número de juvenis na superfície dos tubérculos também foi maior (em média $73,07)$, o que proporcionou um FR superior, com média de 13,08, o que significa que para a segunda espécie a multiplicação dos nematoides foi maior, ou seja, que esta foi mais agressiva (Tabela 3 ).

A ausência de diferenças significativas para a população inicial de nematoides em ambos os experimentos, além dos fatores relacionados à precisão experimental discutidos anteriormente, indicam que, principalmente no primeiro experimento, as áreas apresentavam infecção natural distribuída de maneira uniforme.

Para o primeiro experimento (Tabela 1), verificou-se que os clones F110-01-07, F2109-07, F22-01-08, F97-07-08 e a cultivar Catucha apresentaram a maior multiplicação dos nematoides, com a população final no solo variando de 918,75 a 1737,50 , e FR, variando de 4,71 a 12,72 . Os clones F16102-07, F131-26-08 e F76-01-07 apresentaram FR menor que a unidade $(0,42$, 0,98 e 0,99 , respectivamente), sendo classificados como resistentes, e os demais (F102-22-07, F131-06-08, F156-19-06, F183-08-01 e F50-01-08), apesar de não terem FR menor que a unidade, foram incluídos no mesmo grupo dos clones F16102-07, F131-26-08 e F76-01-07 na análise de agrupamento de médias, com os menores FRs, variando de 1,49 a 2,75. A média do experimento foi de 4,41 .

Quanto ao rendimento de tubérculos, o primeiro experimento (Tabela 2) resultou em menores rendimentos em relação ao segundo experimento. O clone F22-01-08 apresentou o maior número de tubérculos por planta $(20,40)$ e o maior rendimento total de tubérculos $\left(48 \mathrm{t} \mathrm{ha}^{-1}\right)$, mas com reduzida massa média de tubérculos $(57,67$ g), ou seja, tubérculos menores. Sabe-se que plantas que produzem elevado número de tubérculos apresentam, geralmente, tubérculos menores, portanto é importante buscar o equilíbrio na seleção entre número e tamanho de tubérculos (Silva et al. 2012). Os clones F102-22-07, F131-06-08, F13126-08, F161-02-07, F183-01-08 e F97-07-08 apresentaram os tubérculos com os maiores tamanhos médios, porém com reduzido número de tubérculos por planta. Os clones F110-01-07, F21-09-07, F50-01-08, F76-0107 e a cultivar Catucha foram classificados no grupo intermediário, quanto ao número de tubérculos e apresentaram massa média de tubérculos variando de 31,31 a 55,39g.

No segundo experimento todos os clones e cultivares foram considerados suscetíveis (FR>1) a $M$. javanica, e não foi possível diferenciar os genótipos avaliados quanto aos caracteres que medem a população e a multiplicação dos nematoides no solo e nos tubérculos (Tabela 3). Os clones C25191206, F102-22-07 e F37-01-08 apresentaram os tubérculos com as maiores massas médias, porém também os menores números de tubérculos por planta. Os clones F20801-06, F31-05-08, F32-02-06 e a cultivar Asterix apresentaram melhor equilíbrio entre os caracteres de rendimento, agrupados no agrupamento intermediário para a massa total de tubérculos (variação de 40,13 a 47,32 $\mathrm{t} \mathrm{ha}^{-1}$ ), massa média de tubérculos $(122,46$ a $131,67 \mathrm{~g})$ e para número de tubérculos por planta $(7,57$ a 9,50) (Tabela 4).

$\mathrm{Na}$ avaliação de genótipos de batata para reação aos nematoides-das-galhas, Charchar e Moita (1997) avaliaram 38 cultivares de batata, dentre elas uma brasileira e as demais europeias, em campo naturalmente infestado para reação a infecção mista de $M$. incognita raça 1 e $M$. javanica, e verificaram que as cultivares Achat, Esperant e Gigante foram as mais resistentes, com infecção dos tubérculos comerciais inferior a 20\%. Em outro trabalho realizado em campo, Charchar e Moita (2001) avaliaram a 
resistência de 48 genótipos de batata, em sua maioria cultivares importadas, à infecção por $M$. javanica em campo naturalmente infestado. Apesar de observarem valor de FR de 25 na época das águas (novembro a março), classificaram a cultivar Achat como moderadamente resistente, pois a porcentagem de infecção foi menor que para os demais genótipos, $31 \%$. Já em casa de vegetação, Silva et al. (2010) avaliaram a reação de genótipos de batata ('HPC 7 B', Lady Rosetta, Agata, Cupido, Monalisa, Panda, Itararé, Asterix, Capiro, Atlantic, Mayor e Canchan) a $M$. incognita, $M$. javanica e $M$. enterolobii (sin. $M$. mayaguensis) em duas épocas (julho a setembro de 2007 e janeiro a abril de 2008), e observaram nas duas épocas que, aos 60 dias após a inoculação, todos os clones e cultivares apresentaram reprodução das três espécies, sendo que $M$. enterolobii produziu o maior número de ovos. Lima-Medina et al. (2012) avaliaram, em casa de vegetação, 55 dias após a inoculação, nove genótipos de batata (Catucha, BRS Clara, PCD 03-11 (atual BRSIPR Bel), Eliza, BRS Ana, Cristina (atual IPR Cris), Cota, Asterix e Agata) para reação a $M$. incognita, $M$. graminicola, $M$. arenaria e $M$. ethiopica e verificaram que todos os genótipos foram suscetíveis a $M$. incognita, $M$. ethiopica, e $M$. arenaria $(\mathrm{FR}>1)$. Para $M$. graminicola, apenas os genótipos PCD 03-11, Asterix, Cristina, Agata e Eliza foram resistentes (FR < 1). Silva et al. (2010) avaliaram 10 cultivares de batata em casa de vegetação para a reação aos nematoides $M$. incognita, $M$. javanica e $M$. enterolobii.

Dentre as cultivares avaliadas naquele trabalho, Agata e Asterix foram estudadas em comparação a um tomateiro suscetível. Ambas as cultivares apresentaram FR elevado, em média 26,9 e 29,2, respectivamente, próximo aos valores obtidos para o tomateiro $(29,03)$. Ainda com relação àquele estudo, as cultivares Itararé $(3,33)$ e Panda $(5,2)$ apresentaram os menores valores de FR. Schafer et al. (2017) avaliaram em casa de vegetação a reação ao $M$. javanica de três cultivares de batata nacionais BRS Ana, BRSIPR Bel e BRS F63 (Camila) e sete clones de batata, dentre os quais, F23-11-06, F22-01-08, F189-0906, F23-24-06, F38-03-07 e F32-02-06, também avaliados no presente estudo. Todos os genótipos comportaram-se como suscetíveis $(\mathrm{FR}>1)$ naquele estudo. Os valores de FR variaram de 11,3 a 41,3 e foram menores para F22-01-08 (17,8), CL02-05 $(11,3)$ e para as três cultivares testemunhas, e maiores para F23-11-06 $(28,8)$, F189-09-06 (30,0), F23-24-06 $(41,3)$, F38-03-07 $(31,4)$ e F32-02-06 $(36,2)$. LimaMedina et al. (2016) avaliaram nove cultivares de batata em casa de vegetação, dentre elas Catucha, Asterix e Agata, quanto à reação a oito espécies de nematoide-dasgalhas, $M$. javanica, $M$. incognita, $M$. arenaria, $M$. enterolobii, $M$. paranaensis, M. hapla, M. morociensis, e M. graminicola, e verificaram que as cultivares foram suscetíveis a todas as espécies, exceto a $M$. graminicola. As cultivares com menor grau de suscetibilidade a $M$. javanica foram Catucha, Eliza e IPR Cris; a $M$. incognita, Agata; a $M$. hapla, Eliza; a $M$. arenaria, Cota, BRS Clara, Asterix, BRS Ana, Eliza e Agata; a $M$. enterolobii, BRSIPR Bel e Asterix; a $M$. paranaensis, Catucha, BRSIPR Bel, Agata, Asterix, Cota, BRS Clara e BRS Ana; a M. morocciencis, Agata e, a M. graminicola, as cultivares Eliza, IPR Cris e Asterix foram imunes, sendo Agata e Catucha, resistentes.

Observa-se, portanto, com base na ampla literatura e no presente estudo, que há grande variação na resposta de cultivares de batata quanto à resistência para diferentes espécies de nematoides, o que indica a probabilidade de haver vários genes envolvidos na resistência ao nematoide das galhas. Também parece que a reação mais comum dos genótipos de batata aos principais nematoides são 
variáveis níveis de resistência, mas raramente chegam a ser de imunidade. Verifica-se, também, com base em experiência prática, maior proporção de variação ambiental em relação à genética aliada à baixa precisão experimental da maioria dos experimentos, principalmente a campo, e em determinados casos, em casa de vegetação além de pouca correlação de resultados obtidos em local protegido e a resposta a campo. Com base nisso, verifica-se a necessidade de estudos mais aprofundados sobre este assunto, visando aprimorar as metodologias para a obtenção de maior precisão experimental e, ao mesmo tempo, apresentar, na prática, viabilidade para a avaliação de grande quantidade de clones para a reação ao nematoide-das-galhas.

Pode-se verificar, portanto, que para o primeiro experimento, quanto à reação ao M. incognita, com exceção dos clones F161-02-07, F131-26-08 e F76-01-07, que foram classificados como resistentes, os demais foram considerados suscetíveis com FR maior que a unidade. Os clones F102-22-07, F131-06-08, F156-19-06, F183-08-01, F50-01-08 e F76-01-07 apesar de apresentarem FR maior que a unidade, foram incluídos no mesmo grupo dos clones F161-02-07, F131-26-08 e F76-0107. Os clones F22-01-08, F102-22-07, F131-06-08, F131-26-08, F161-02-07, F183-01-08 e F97-07-08 apresentaram os melhores resultados para caracteres relacionados ao rendimento de tubérculos. No segundo experimento, todos os clones e cultivares foram suscetíveis a $M$. javanica, e não houve diferença entre os genótipos quanto à população e a multiplicação dos nematoides no solo e nos tubérculos. Os clones C2519-1206, F102-22-07 e F37-0108, F208-01-06, F31-05-08, F32-02-06 apresentaram os melhores resultados para caracteres relacionados ao rendimento de tubérculos.

\section{Conflitos de interesse}

Esta pesquisa não apresenta conflitos de interesse.

\section{Referências Citadas}

Almeida, F.A.; Petter, F.A.; Siqueira, V.C.; Alcântara Neto, F.; Alves, A.U.; Leitem M.L.T. (2012). Modos de preparo de extratos vegetais sobre Meloidogyne javanica no tomateiro. Nematropica 42:915.

Carneiro, R.M.D.G.; Almeida, M.R.A. (2001). Técnica de eletroforese usada no estudo de enzimas dos nematoides de galhas para identificação de espécies. Nemat. Bras. $25: 35-44$

Charchar, J.M. (2001). Ciclo de vida de Meloidogyne spp. em batata. Brasília: Embrapa Hortaliças (Boletim de Pesquisa e Desenvolvimento, 1), 20p.

Charchar J.M.; Moita, A.W. (1997). Reação de cultivares de batata a uma infestação mista de Meloidogyne incognita raça 1 e $M$. javanica. Nemat. Bras. 21:39-48.

Charchar J.M.; Moita, A.W. (2001). Resistência de genótipos de batata a Meloidogyne javanica. Pesq. Agrop. Bras. 36:535-540.

Cruz, C.D. (2013). Genes: a software package for analysis in experimental statistics and quantitative genetics. Acta Scient. Agron. 35:271-276.

Cruz, C.D.; Regazzi, A.J.; Carneiro, P.C.S. (2012). Modelos biométricos aplicados ao melhoramento genético. $4^{\mathrm{a}}$.ed. Viçosa: Editora UFV. 514p.

Freitas, L.G.; Oliveira, R.D.L.; Ferraz, S. (2001). Introdução à nematologia. Viçosa: Editora UFV, 84p.

Hussey, R.S.; Barker. K.R. (1973). A comparison of methods of collecting inocula of Meloidogyne spp., including a new technique. Plant Disease Reporter 57:10251028.

Jenkins, W.R. (1964). A rapid centrifugal flotation technique for separating nematodes from soil. Plant Disease Reporter 48:692695. 
Lima-Medina, I.; Gomes, C.B.; Somavilla, L.; Signorini, C.H.B.; De Brum, D. (2012). Resistência varietal de cultivares y clones de papa al nematodo del nudo de la raiz (Meloidogyne spp.). In: Congreso de la Associación Latinoamericana de la Papa, 25. Encontro Nacional de Produção e Abastecimento de Batata, 14. Uberlândia: Associacion Latinoamericana de la Papa. CD-ROM. 18.

Lima-Medina, I., Bellé, C.; Casa-Coila, V.H.; Pereira, A. DA S.; Gomes, C.B. (2016). Reação de cultivares de batata aos nematoides-das-galhas. Nematropica 46:188-196.

Lima-Medina, I., Casa-Coila, V.H.; Gomes, C.B.; Pereira, A.S.; Nazareno, N.R.X. (2014). Ocorrência de Meloidogyne ethiopica no Paraná e reação de cultivares de batata ao nematoide das galhas. Hort. Bras. 32:482-485.

Oostenbrink M. (1966). Major characteristics of the relation between nematodes and plants. Mededelingen Landbouw 66:1-46.

Pinheiro, J. B.; Carvalho, A.D.F.; Rodrigues, C.S.; Pereira, R.B.; Suinaga, F.A. (2013). Reação de clones avançados de batata em campo naturalmente infestado pelo nematoide-das-galhas. Embrapa Hortaliças. Boletim Pesquisa e Desenvolvimento 99. 18p.

Pinheiro, J. B.; Lopes C.A. (2011). Manejo integrado de nematoides em cultivos de batata, p. 69-94. In: Zambolim, L. Produção integrada da batata. Volume 2. Viçosa: Universo Agrícola.

Prasad, K.S.K. (1993). Nematodes distribution, biology and management. Advances in Horticulture 7:635-647.

Scott, A. J.; Knott, M. (1974). A cluster analysis method for grouping means in the analysis of variance. Biometrics 30:507-512.
Schafer, J. T.; Gomes, C.B.; Pereira, A.S.; Cruz, F.F.; Barros, D.R. (2017). Resistance of potato genotypes to Meloidogyne javanica. Rev. Caatinga 30:536 - 540.

Silva, A. R.; Santos, J.M. (2007). Nematoides na cultura da batata no Brasil. 1a Edição, São Paulo, Associação Brasileira da Batata - ABBA, 55p.

Silva, A. R.; Santos, J.M.; Hayashi, P.C.R.; Hayashi, E. (2010). Reação de clones e cultivares de batata avaliados em casa de vegetação a Meloidogyne incognita, $M$. javanica e $M$. mayaguensis e in vitro a $M$. javanica. Nemat. Bras. 34:48-55.

Silva, G. O.; Pereira, A.S.; Souza, V.Q.; Carvalho, F.I.F.; Neto, R.F. (2006). Early generation selection for tuber appearance affects potato yield components. Crop Breeding and Applied Biotec. 6:73-78.

Silva, G.O.; Castro, C.M.; Terres, L.R.; Rohr, A.; Suinaga, F.A.; Pereira, A.S. (2012). Desempenho agronômico de clones elite de batata. Hort. Bras. 30:557-560.

Silva, A.R.; Santos, J.M. (2007). Nematoides na cultura da batata no Brasil. $1^{\text {a }}$ Edição, São Paulo, Associação Brasileira da Batata - ABBA, 55p.

Starr, J.L.; Roberts, P.A. (2004). Resistance to plant parasitic nematodes. In: Chen, $\mathrm{Z}$. N.; Chen, S.Y.; Dickson, D.W. (eds). Nematology, Advances and Perspectives, v.2. Wallingford: CAB International, p. 879907.

Taylor, A.; Sasser, J.N. (1978). Biology, identification and control of root-knot nematodes (Meloidogyne species). Cary: North Caroline State University Graphics, $111 \mathrm{p}$.

Vovlas, N.; Mifsud, D.; Landa, B.B.; Castillo, P. (2005). Pathogenicity of the root-knot nematode Meloidogyne javanica on potato. Plant Pathology 54: 657-664. 